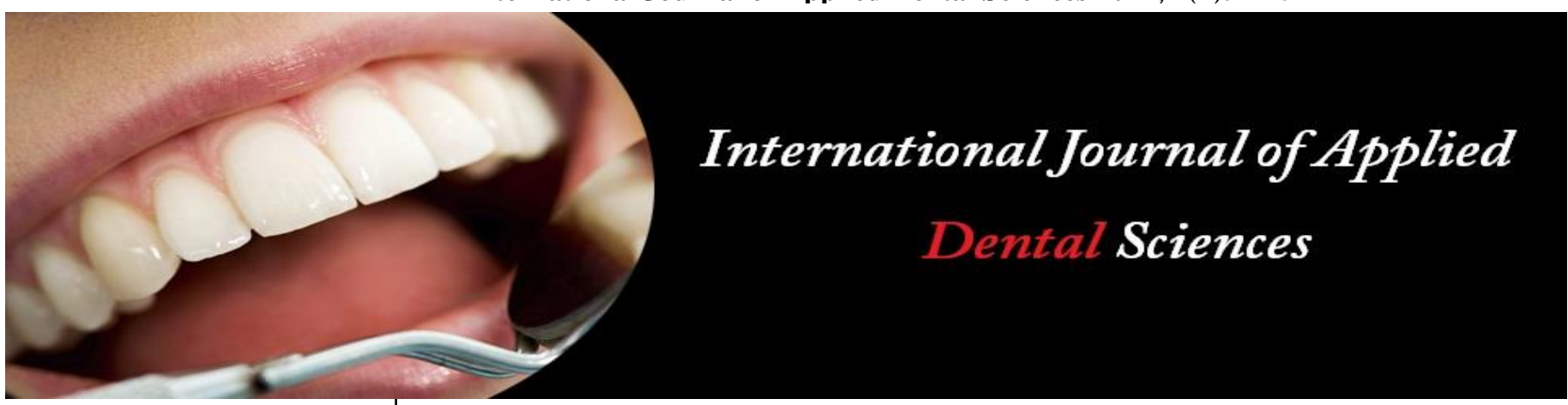

ISSN Print: 2394-7489

ISSN Online: 2394-7497

IJADS 2021; 7(1): 44-52

(C) 2021 IJADS

www.oraljournal.com

Received: 23-11-2020

Accepted: 28-12-2020

Dr. Bhavya Reddy Chethi Reddy

1. BDS, Government Dental

College and Hospitals,

Vijayawada, Andhra Pradesh,

India

2. MPH, Deakin University,

Melbourne, Australia
Corresponding Author: Dr. Bhavya Reddy Chethi Reddy 1. BDS, Government Dental College and Hospitals,

Vijayawada, Andhra Pradesh, India

2. MPH, Deakin University, Melbourne, Australia

\section{Current dental strategies and interventions to enhance the practice of dental professionals when treating children with autism: A systematic review}

\section{Dr. Bhavya Reddy Chethi Reddy}

DOI: https://doi.org/10.22271/oral.2021.v7.i1a.1117

\section{Abstract}

Background: Autism is a neurological disorder which can be associated with impaired behavioural patterns, expressive and receptive communication difficulties and challenges with social interaction. When combined these challenges can make dental treatment difficult. Therefore, dentists need to be skilled in appropriate dental management strategies for children with autism who attend their clinics for treatment.

Rationale: Previous literature reviews have identified the use of traditional behavioural management techniques, such as physical restraints and general anaesthesia. This study aims to update the existing reviews and report effective contemporary techniques.

Aim of the review: This literature review aims to document and record current dental strategies and techniques in treating children with autism.

Methods: A systematic literature search within PubMed and EBSCO Host using the search terms "Dental strategies" OR dental techniques OR Dental manag* OR dental treat* OR dentist AND autism AND Child* was carried out. The search yielded 10 articles, once exclusion and inclusion criteria were applied and each article was assessed using the qualitative and quantitative CASP tools.

Results: Four main themes emerged from a thematic analysis of the 10 articles:

1) Desensitization strategies.

2) Educational strategies.

3) Behavioural approaches.

4) Anaesthesia interventions.

Evidence showed that current dental strategies like inter- professional collaboration and some visual strategies using the electronic screen media were particularly effective in treating children with autism within the clinical setting.

Conclusion: A range of strategies in providing dental treatment to children with autism were identified. These strategies include desensitization, by various techniques (e.g. visual strategies and social stories, desensitization appointments), educational strategies (e.g. inter-professional collaboration), behavioural strategies and local anaesthesia. However, there is limited evidence regarding the effectiveness of these techniques particularly local anaesthesia and communication supports. Future research is needed to ascertain the effectiveness of these techniques, both in their own right and comparatively with each other.

Keywords: dental strategies, autism, interventions

\section{Introduction}

Autism is a neurological disorder which is characterized by impaired behavioural patterns, difficulties with communication and challenges with social ${ }^{[1]}$. While the exact cause of autism remains unknown, genetic or environmental factors contribute to autism incidence. To date, there is no cure for autism ${ }^{[2]}$. However, some behavioural, sensory and educational techniques as well as drug therapies have been found to improve the condition ${ }^{[3]}$. 
According to WHO, about 1 in 160 children have autism.

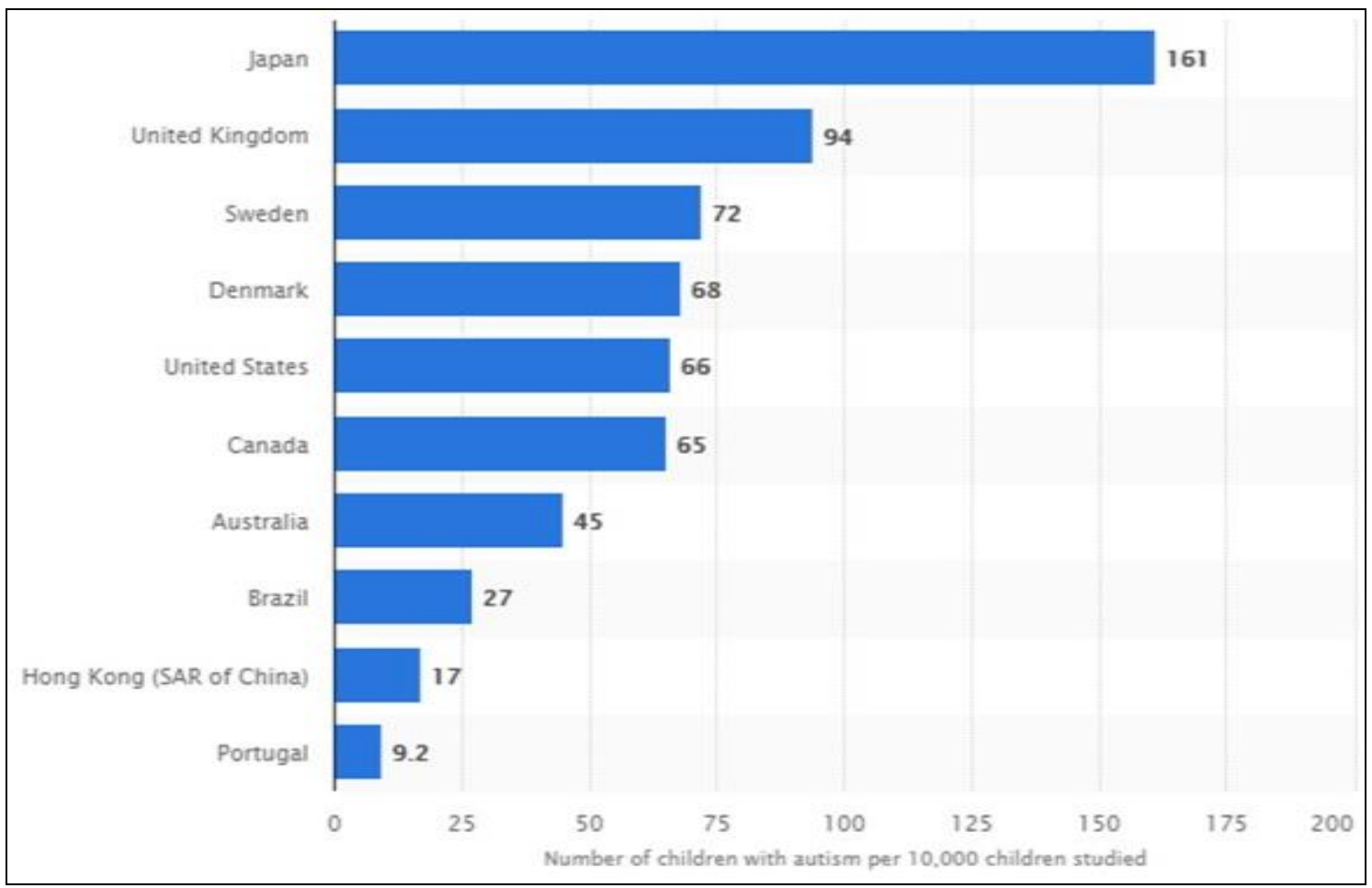

https://www.statista.com/statistics/676354/ autism-rate-among-children-select- countries-worldwide/

Fig 1: Prevalence of autism among children globally in selected countries

Children with autism are at the risk of poor oral health due to a range of individual and environmental factors ${ }^{[1]}$. They often have limited manual dexterity which makes it hard to perform necessary daily activities such as brushing teeth. Having difficulty in performing and maintaining personal oral hygiene, children with autism tend to have poorer oral health. Due to difficulties with understanding verbal instruction dental treatment within a clinical setting can be challenging [3] Gandhi \& Klein ${ }^{[1]}$ and Cruz et al. ${ }^{[3]}$ found that some parents offer food as a reward to their children or use food to calm them. Most of these rewards contain carbohydrates, starches and other sticky foods which increase dental caries susceptibility and/or speed up the progression of carious lesions. Starchy diet stimulates bacterial film accumulation on tooth surface and development of calculus (hard depositions on teeth). Thus, due to the various risk factors, patients with autism require special management in the dental clinic ${ }^{[3]}$.

A range of techniques are available to dentists when treating children in paediatrics dentistry but only a few techniques exist that are specifically designed for children with autism ${ }^{[4]}$. My practice experience provides further insights.

Some of the children I have treated with autism can cooperate with traditional dental treatment very well, but for some, particularly children with sensory difficulties and anxiety dental treatment can be difficult. Physical restraints and general anaesthesia are generally applied in these challenging cases. I found that children used to have post-operative complications due to limited knowledge of parents and limited parent-professional communication. A case that inspired me to pursue this research was a child with autism who had oral myiasis, this is a rare disease effected by the larvae of the flies turning into moths which is mostly seen in the developing countries. I found this case very disturbing and it motivated me to search the literature to gain knowledge about customised techniques in treating children with autism.
Two recent literature reviews published in 2013 and 2014 reported various dental strategies such as behaviour management and other techniques [5, 1]. Behaviour management techniques included the use of social stories, positive reinforcement and tell-show-do techniques. Other techniques referred to physical restraint, general anaesthesia and medication. These dental strategies are summarised in Table 1 below.

Table 1: literature review on dental strategies for children with autism

\begin{tabular}{|c|c|}
\hline $\begin{array}{c}\text { Behaviour } \\
\text { management }\end{array}$ & Techniques \\
\hline $\begin{array}{l}\text { Social stories } \\
\text { through books }\end{array}$ & Books are used to teach social skills ${ }^{[1]}$. \\
\hline $\begin{array}{l}\text { Positive } \\
\text { reinforcement }\end{array}$ & $\begin{array}{c}\text { Reward that is given to the children after } \\
\text { apositive outcome of their behaviour during } \\
\text { treatment and this reward is repeated after every } \\
\text { positive outcome }\end{array}$ \\
\hline $\begin{array}{l}\text { Tell-show-do } \\
\text { technique }\end{array}$ & $\begin{array}{l}\text { A traditional and routine technique used by } \\
\text { almost all dentist where children are told about the } \\
\text { treatment, instruments and procedure is shown to } \\
\text { the children and then done with their concern }{ }^{[1]}\end{array}$ \\
\hline $\begin{array}{c}\text { Non-behaviour } \\
\text { management }\end{array}$ & Techniques \\
\hline $\begin{array}{l}\text { Physical } \\
\text { restraints }\end{array}$ & $\begin{array}{l}\text { Use of any physical methods and materials like } \\
\text { Pedi-wraps to control the child's behaviour and } \\
\text { to reduce the capacity of self-harming }[1,5]\end{array}$ \\
\hline $\begin{array}{c}\text { General } \\
\text { anaesthesia }\end{array}$ & $\begin{array}{l}\begin{array}{l}\text { Sedative procedure generally performed where the } \\
\text { child is completely anaesthetized to receive dental } \\
\text { treatment }\end{array}{ }^{[1]} \\
\end{array}$ \\
\hline $\begin{array}{l}\text { Anti-psychotic } \\
\text { drugs }\end{array}$ & $\begin{array}{c}\text { Medication to treat children with anxiety, } \\
\text { depression and irritability }[5]\end{array}$ \\
\hline
\end{tabular}

There is a clear gap in the research literature regarding personalised dental management strategies for individual children with autism. Each child has diverse needs and 
respond differently to management techniques. Hence, there is a need for customised dental treatment rather than creating generalised treatment options for all the children with autism ${ }^{[6]}$. Given the existing reviews in this topic were published in 2014, the main objective of this literature review is to document and record the contemporary dental strategies and techniques which enhance the practice of dental professionals while treating children with autism within a clinical setting.

\section{Methods \\ Search strategy}

The search strategy was comprised of multiple stages carried out over a period of 6 weeks. The first stage involved searching the literature using the following search strings "oral health or dental hygiene and autism", "dental management or dental strategies", "autism and children and autism" and "dental management and children". These search strings were applied to two databases, PubMed and EBSCO host. These data bases were selected as they are most recommended in the Deakin library as excellent sources of information and due to the author's previous experiences and convenience in using them. Three hundred articles were found, out of which 53 were selected according to the selection criteria. The included articles were published from 2010 onwards. It was decided that it would be beneficial for the author to update two existing literature reviews. These reviews were Ghandi \& Klien $2014^{[1]}$ and Delli $2013^{[5]}$.
A lot of time was spent exploring a range of search strings, finding that different search terms revealed extremely varied results. For example, when the word 'oral' was added many irrelevant articles were identified, for instance, oral contraceptive, oral speech, oral cancer and oral herpes.

The final search terms are "Dental strategies" OR dental techniques OR Dental Manag* OR dental treat* OR dentist AND autism AND Child. PubMed and EBSCO host were searched, and 2353 articles were found. Four hundred and fifty-seven (457) duplicates were removed using endnote and a total of 1896 articles were included for screening. After applying the inclusion criteria (see Table 2) along with title and abstract screening 1797 articles were excluded. Ninetynine (99) articles were reviewed for full text screening and 84 articles were excluded based on their unavailability at the Deakin university library and also data irrelevancy. This process revealed 15 articles including 1 qualitative study, 2 randomised controlled studies, 1 longitudinal study, 6 systematic reviews, 1 clinical trial, 1 quasi- experimental study and 1 cross-sectional study. These were further assessed in terms of quality using several CASP tools, and a final list of ten articles were selected for review. An explanation of the quality assessment is outlined below and the results from these assessments are summarised in Tables 3 to 7 . The entire process is depicted in Figure 2.

\section{Inclusion and exclusion criteria}

Table 2: Inclusion and exclusion criteria

\begin{tabular}{|c|l|l|}
\hline $\begin{array}{c}\text { Inclusion } \\
\text { criteria: }\end{array}$ & $\begin{array}{l}\text { This literature review included articles published in English between } 2014 \text { and 2018. The review provides an overview and } \\
\text { analysis of articles exploring new dental strategies and an update of old strategies employed in Ghandi \& Klein } 2014 \text { and Delli } e t \\
\text { al. } 2013^{[1,5]}\end{array}$ \\
\hline $\begin{array}{l}\text { Studies that focused on strategies used with children with autism in a clinical setting were selected. } \\
\text { A variety of qualitative, randomised controlled trials and literature reviews, clinical trials, cross-sectional studies published in } \\
\text { academic journals were included in this review. }\end{array}$ \\
$\begin{array}{c}\text { Exclusion } \\
\text { criteria: }\end{array}$ \\
$\begin{array}{l}\text { Non-academic journals. } \\
\text { The articles which are not specifying the children with autism. } \\
\text { Articles which are showing just the oral health implications on autism children but not emphasising on treatment strategies. } \\
\text { Articles which are not appropriate when critically appraised using CASP. }\end{array}$ \\
\hline
\end{tabular}

\section{Quality assessment}

The value of the study or review is analysed by viewing the quality assessment of their included studies [7]. Therefore, each article was critically appraised using the CASP suite of tools. These tools were selected as they are widely used and can be implemented in a short period of time. There are two screening questions in the beginning of each checklist which allow the reviewer to make a rapid decision as to whether or not they will proceed for further investigation. In addition, each question has a hint guide which makes it easy for the researcher to understand ${ }^{[8]}$. A wide range of articles were assessed using a number of CASP tools. The results from these assessments are summarised in Tables 3 to 7.

\section{Analysis of randomised controlled trial studies using CASP checklist}

The questions that were used in this checklist are designed to help the research think about the study systematically, there are screening questions which guide in proceeding with the analysis or not, the analysis is done by using yes, no and can't

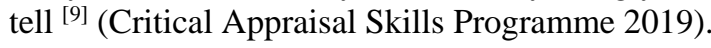

Table 3: Critical analysis of randomised controlled trial

\begin{tabular}{|c|c|c|}
\hline CASP randomised controlled trial checklist & $\begin{array}{c}\text { Mah and } \\
\text { Tsang 2016 }\end{array}$ & $\begin{array}{c}\text { Isong } \text { et } \\
\text { al. 2014 }\end{array}$ \\
\hline Clear focus of issue & Yes & Yes \\
\hline Randomised assessment of patients & Yes & Yes \\
\hline Appropriate strategy in recruitment & Yes & Yes \\
\hline Same group of participants till the end & Yes & Yes \\
\hline Equal treatment of groups & Yes & Yes \\
\hline Clear specification of primary outcome & Yes & Yes \\
\hline Were the patients properly accounted? & Yes & Yes \\
\hline Were the results clearly analysed & Yes & Yes \\
\hline Results applicable to normal population & Yes & Yes \\
\hline All clinically important outcome considered & Yes & Yes \\
\hline
\end{tabular}

\section{Analysis of qualitative study using CASP Checklist}

In this checklist the first two questions are considered to be the screening questions and if the answer for these questions is yes then it is worth proceeding forward ${ }^{[9]}$.

\section{Analysis of systematic reviews using CASP checklists for systematic reviews}

As mentioned above for other studies, even the systematic review checklist is designed such that the first two questions are quickly and easily answerable ${ }^{[9]}$ we screened five articles out of which two articles were included in the review as they answered yes for almost all the questions in the checklist. 
Table 4: Critical analysis of systematic reviews

\begin{tabular}{|c|c|c|c|c|c|}
\hline CASP Systematic review checklist & Nelson et al. 2015. & Shree et al. 2018 & Elmore et al. 2016 & Bartolomé-Villar et al. 2016 & (Baek K, 2015) \\
\hline
\end{tabular}

\begin{tabular}{|c|c|c|c|c|c|}
\hline & & & & & \\
\hline Question clearly focused & Yes & \begin{tabular}{|c|} 
Ye s \\
\end{tabular} & \begin{tabular}{|c|} 
Yes \\
\end{tabular} & \begin{tabular}{|c|} 
Yes \\
\end{tabular} & Yes \\
\hline Right papers reviewed & Yes & Ye s & Yes & Yes & Yes \\
\hline Relevant studies included & Yes & No & Yes & No & Yes \\
\hline Proper quality assessment done & Yes & No & Yes & Yes & No \\
\hline $\begin{array}{l}\text { Was the used Method ology } \\
\text { appropriate and complete? }\end{array}$ & Yes & Yes & Yes & Yes & No \\
\hline Were the results combined & Yes & Yes & Yes & No & No \\
\hline Are the results accurate? & Yes & No & Yes & No & Yes \\
\hline $\begin{array}{c}\text { Results applicable to the typically } \\
\text { developing population }\end{array}$ & Yes & Yes & Yes & Yes & Yes \\
\hline $\begin{array}{l}\text { Consideration of important outcomes } \\
\text { is seen }\end{array}$ & Yes & No & Yes & Yes & No \\
\hline $\begin{array}{c}\text { Benefits overweighing the costs and } \\
\text { harms }\end{array}$ & Yes & No & Yes & No & No \\
\hline
\end{tabular}

Analysis of quasi- experimental study

As this paper satisfied all the questions in the checklist, it is included for review.

Table 5: Critical analysis of quasi-experimental study

\begin{tabular}{|c|c|}
\hline CASP Quasi-experimental design Checklist & Marion et al. 2016 \\
\hline Clear statement of study, cause and effect & Yes \\
\hline $\begin{array}{c}\text { Were the included participants similar in any } \\
\text { comparison? }\end{array}$ & Yes \\
\hline Comparisons receiving similar treatment & Yes \\
\hline Control group is present & Yes \\
\hline Were there various measures of the outcome & Yes \\
\hline $\begin{array}{c}\text { Were the outcomes of participants included in } \\
\text { any comparisons measured in the same way? }\end{array}$ & Yes \\
\hline Were outcomes measured in a reliable way? & Yes \\
\hline $\begin{array}{c}\text { Was the usage of statistical analysis reliable and } \\
\text { appropriate? }\end{array}$ & Yes \\
\hline
\end{tabular}

\section{Analysis of longitudinal study}

Table 6: Critical analysis of longitudinal study

\begin{tabular}{|c|c|}
\hline Longitudinal study checklist & Zink et al. 2016) \\
\hline $\begin{array}{c}\text { Clear focused issue addressed } \\
\text { way }\end{array}$ & Yes \\
\hline $\begin{array}{c}\text { Is the recruitment of the cohort in an acceptable } \\
\text { Was there a minimum bias and accurately } \\
\text { measured exposure? }\end{array}$ & Yes \\
\hline $\begin{array}{c}\text { Was there a minimum bias and accurately } \\
\text { measured outcome? }\end{array}$ & Yes \\
\hline Important confounding factors identified & Yes \\
\hline Confounding factors included in analysis & Yes \\
\hline Was there an enough complete follow up & Yes \\
\hline Are the results accurate? & Yes \\
\hline $\begin{array}{c}\text { Can the results be applied to the typically } \\
\text { developing population? }\end{array}$ & Yes \\
\hline Is the study using supporting evidences? & Yes \\
\hline
\end{tabular}

\section{Analysis of the clinical study}

Table 7: Critical analysis of clinical study

\begin{tabular}{|c|c|c|}
\hline CASP clinical trial checklist & $\begin{array}{c}\text { Fakhruddin and } \\
\text { Batawi, 2017 }\end{array}$ & $\begin{array}{c}\text { Jo } \text { et al. } \\
\mathbf{2 0 1 7}\end{array}$ \\
\hline $\begin{array}{c}\text { Were the demographic details of the } \\
\text { patient mentioned clearly? }\end{array}$ & Yes & Yes \\
\hline $\begin{array}{c}\text { Was the medical and dental history of } \\
\text { the patient mentioned clearly? }\end{array}$ & Yes & Yes \\
\hline $\begin{array}{c}\text { Was the current clinical condition of the } \\
\text { patient considered and mentioned }\end{array}$ & Yes & Yes \\
\hline
\end{tabular}

\begin{tabular}{|c|c|c|}
\hline clearly? & Yes & Yes \\
\hline $\begin{array}{c}\text { Diagnostic tests or assessment methods } \\
\text { and the results clear }\end{array}$ & Yes & Yes \\
\hline $\begin{array}{c}\text { Interventions and treatment procedures } \\
\text { clearly described }\end{array}$ & Yes & Yes \\
\hline $\begin{array}{c}\text { Was the post-intervention clinical } \\
\text { condition considered adequately? }\end{array}$ & Yes & Yes \\
\hline $\begin{array}{c}\text { Anticipation of adverse effects of } \\
\text { treatment and solutions of them } \\
\text { described }\end{array}$ & Yes & Yes \\
\hline $\begin{array}{c}\text { Were there any takeaway lessons from } \\
\text { the case-study }\end{array}$ & & \\
\hline
\end{tabular}

Finally, after applying application of CASP tool to assess the quality of 15 articles, 10 articles were selected for review. The entire process is depicted in figure 2 .

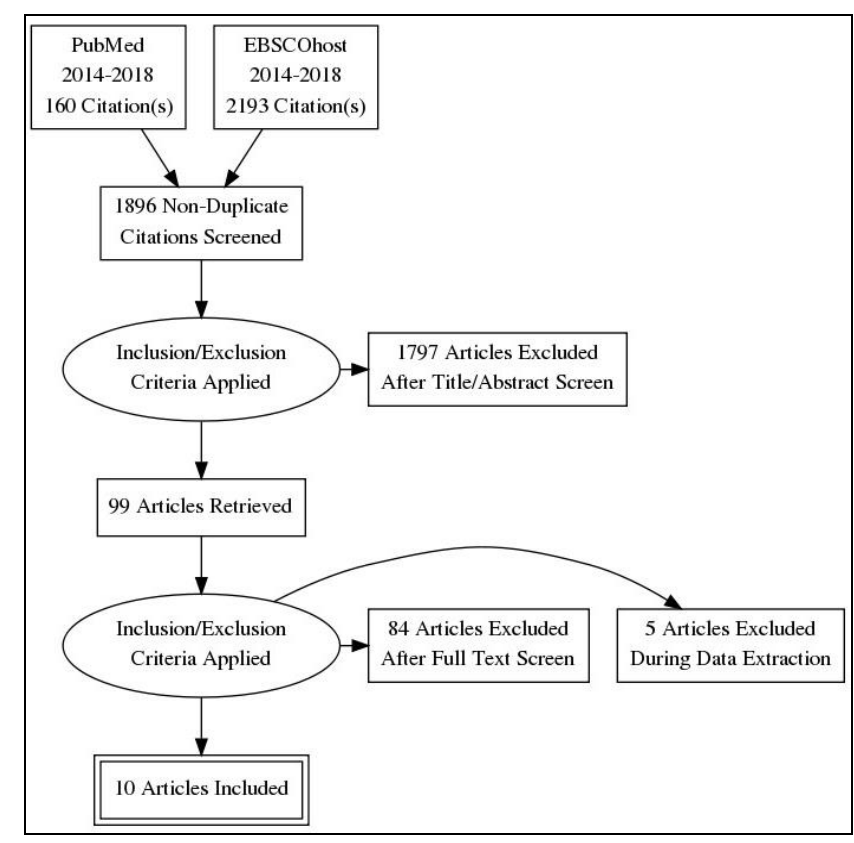

Fig 2: Prisma diagram showing search strategy

\section{Data extraction and analysis}

The ten included studies were thematically analysed to achieve the objective of ascertaining current interventions used by dental professionals in treating children with autism. This thematic analysis involved the identification of themes and subthemes, all of which are discussed in the remainder of this thesis.

\section{Results/Findings}

The main themes that emerged from the thematic analysis 
undertaken as part of this review were: Sensitization strategies, educational strategies, behavioural approaches and anaesthesia technique (Figure 3). Pre-treatment strategies refer to dental stories and other preparatory aids. Educational strategies include inter-professional collaboration. Behavioural approaches include educational and therapeutic behavioural approaches, cognitive behavioural intervention, patient- professional communication strategies. Anaesthesia strategies include techniques such as submucosal sedation.

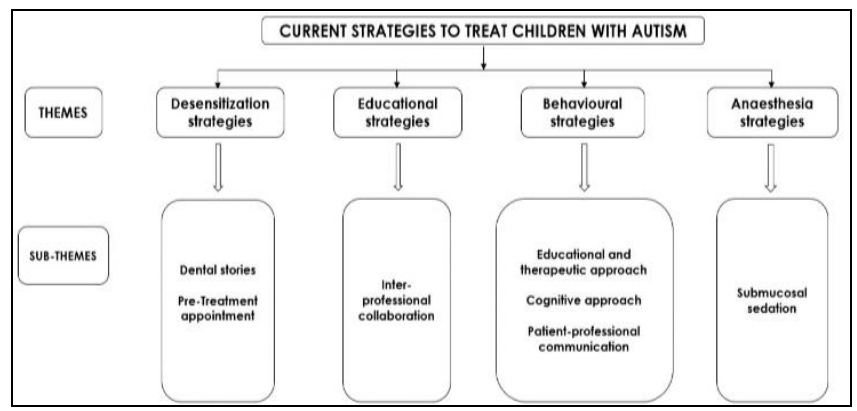

Fig 3: Data Analysis using thematic analysis

The main strength of this review is the use of both qualitative and quantitative studies to maximise the findings. As in this review we included quasi-experimental, randomised control trials, longitudinal studies ${ }^{[10,11,12]}$ and qualitative study ${ }^{[13]}$. the results of each study is explained below in detail following the analytical order.

\section{Desensitization strategies}

Dental appointments can be challenging for both children with autism and their treating clinician. However, effective desensitization programs can help these children overcome fear and anxiety related to treatment. Desensitization includes pre- visit preparation of children at home using social stories, repeated dental visits to help familiarise children with the clinical environment, including allowing them to see and touch equipment that will be used during their treatment ${ }^{[14]}$. Children with autism may find it difficult to cooperate during dental treatment due to their difficulties with communication and integrating sensory experiences ${ }^{[10]}$. To address such challenges social stories were used. These social stories were introduced to children before their visit. These stories provided a positive narrative of the upcoming dental experience. These stories were evaluated by dental hospitals to ascertain if they are effective by conducting a survey. Forty initial and 16 follow-up surveys were conducted and $64 \%$ of the caregivers reported that the stories were useful not only for their child but for themselves. Fourteen percent reported that these stories were useful only for them, and not for their children. These dental stories contained information regarding home based oral care, preparation of the child before coming to the dental clinic, and various images and videos. Marion and colleagues concluded that the use of social stories was effective in increasing understanding of dental treatment by parents and they impacted positively on the child's behaviour [10]

This is supported by a Saudi Arabian study by Murshid. This study evaluated the impact of dental books on behavioural patterns, changes in oral health and parent's awareness. The study showed that the introduction of dental books prior to treatment were effective in enhancing the awareness of dental knowledge. Scores were given to the children based on dental problems, brushing techniques and behaviour during the treatment. Parental feedback indicated a preference for digital stories. However, some caregivers also requested for stories to be provided in print ${ }^{[11]}$.

\section{Educational strategies}

Inter-professional collaboration (IPE) in dentistry refers to collaboration of dental professionals with other professionals (e.g., speech pathologists) to improve patient health outcomes, enhance their experiences as well as to expand the knowledge of professionals ${ }^{[13]}$.

Relevance of this intervention was tested by Anderson and Carlson by conducting a pilot project among students of 2 profession, Speech pathology and Dental hygiene. In this study students of both disciplines were given four children with autism with dental needs. Students were asked to create effective visual strategies (digital social stories, visual lessons) for their assigned. For instance, dental students were given an opportunity to observe the child's behaviour, signs and symptoms while Speech pathology students conducted speech language sessions. After completion of the sessions all the students collaborated to create visual strategies which would help children for dental prophylaxis and screening ${ }^{[13]}$. Results of this study revealed that the students of both disciplines learnt a lot about roles and responsibilities. They are now very confident recognising the signs and symptoms of autism and in creating strategies. Anderson and Carlson concluded that there is value in introducing IPE to increase the standards of treatment ${ }^{[13]}$.

A systematic review was conducted by Bodison and Praham to examine the effectiveness of sensory techniques in improving the participation of child with autism during medical and dental treatment. They found that children with sensory integration difficulties benefitted from different sensory techniques such as qigong massage and swing activities managed by occupational therapists. Such activities had the positive impacts of calming over excited children, improving self-regulatory behaviour and other tactile abnormalities ${ }^{[15]}$. Qigong massage is basically provided by occupational therapist, but as children with difficulties are closer to the caregivers and parents, this procedure is explained to the parents. This includes 15 minutes of massage for 4 to 5 months and findings suggests that this massage have developmental and behavioural benefits after 4 to 5 months of therapy, Bodison and Praham also stated the importance of collaboration of occupational therapists and dental professionals to explore their practice and new interventions in their systematic review ${ }^{[15]}$.

\section{Behavioural strategies}

\section{Educational and therapeutic behavioural approaches}

The primary focus of Educational and therapeutic behavioural approaches is to children with Autism Spectrum Disorder (ASD) is to enhance the treatment quality.

A literature review conducted by Nelson and his colleagues revealed that behavioural changes in children with autism often become a barrier in receiving optimum dental care. Often techniques such as general anaesthesia and restraints for protective stabilization are applied in such conditions but are not always effective. Therefore, interventions like the creative educational approach used for children with autism by occupational therapists, speech pathologists as well as parents at home were applied in a dental setting. These interventions included the use of social stories, visual teaching strategies (e.g. videos of brushing techniques, dental setting, dental stories) and sensory integration ${ }^{[14]}$. Nelson also found that there is value in ensuring visits to dental appointments are 
short and that wait time during the appointment be minimized. This need for minimal waiting time should be considered when scheduling of appointments. Children with autism may also have difficulties with attention. Therefore, Nelson concluded that appointments must be divided into manageable chunks. This also helps to prepare the child for dental visits in a positive way for the lifetime ${ }^{[14]}$.

Nelson also highlights the importance of consulting with caregivers in order to know how best to support the child. This involves investment of extra time in order to understand each child as an individual in order to make accommodations for supporting these children. This way the dentists are able to gain the trust of the children along with the confidence of the child and the family ${ }^{[14]}$.

\section{Cognitive behavioural intervention Electronic media}

Supporting the educational and therapeutic strategies use of visual strategies is most preferable by children with autism as they appear to have a strong preference for visual stimuli. These children require special attention in a clinical setting due to comorbidities such as anxiety and fear associated with unusual responses to sensory stimuli (e.g. fear of light in eyes, fear of sounds from Aeroter and scalars, fear of touch) ${ }^{[12]}$. A randomised control trial was conducted at Boston children's dental clinic on 80 children. The children were divided into four groups to evaluate the efficacy of using visual strategies by electronic screen media ${ }^{[12]}$. One group used video peer modelling, which entailed the use of a DVD which introduced the treatment protocol and the instruments to be used in the form of a friendly video). A second group used, video goggles (video eyewear resembling sunglasses playing movies) to distract the child from dental procedure). A third group used both these interventions and a fourth control group used none. The subject's behaviour and anxiety levels were measured by the Venham behaviour and anxiety scale ${ }^{[12]}$. The results showed a significant decrease in anxiety and fear in children who were randomised to distraction by the movie. The children who used DVD suggesting that the distraction best works to divert the attention in children with extreme fear and education adds to the cognitive development ${ }^{[12]}$.

The effectiveness of audio-visual distraction is also evaluated by a clinical study conducted by Fakhruddin and Batawi on 28 children for early detection and preventive restorations and oral prophylaxis. This study was performed in 4 sessions which included an initial desensitising appointment. Each session had 1-week gap in between in which parents were given powered tooth brushes to familiarise their child with the oscillating and rotating nature of similar dental instruments. In the successive sessions video eye googles were used to distract the child. While conducting session 2 and 3 pulse rate and blood oxygen saturation were recorded using pulse oximeter every 5 minutes ${ }^{[16]}$. Results showed a significant difference in mean pulse rate of children who were watching cartoon movies through eye goggles. This study demonstrates the value of using visual strategies as a cognitive behavioural intervention ${ }^{[16]}$.

\section{Patient-professional communication strategies Picture exchange communication system (PECS)}

Zink and his colleagues described the picture exchange communication system as a widely used technique for children who are early learners with autism. This system uses pictures of daily life laminated and stuck to a board which is easily removable. For instance, if a child wants a chocolate or a toy he is trained to give the related picture to the parent in order to get it. The usage in dentistry is limited and almost no report of its usage is registered ${ }^{[17]}$.

Hence a longitudinal pilot study was conducted by Zink along with his colleagues in which 26 children with autism were selected by dental professionals and divided into 2 groups. One group had previous experience with dentists and the other group had no experience. They prepared seven figures fixed to a plastic board to aid the child in understanding the sequence of simple procedures. The sequence included a picture of a consultation room (room), reception (ground), dental chair (chair), dentist, mouth, low speed hand piece (low), triple syringe (triple). Initially visual contact was the main aim for which head gears were used to adapt later each participant is given three chances to identify and establish contact, after all the sessions and acquiring the knowledge children were given oral prophylaxis. Patients without previous dental visits accepted the PECS in few attempts while the children with previous experiences expressed fear and anxiety and also took lot of attempts to accept ${ }^{[17]}$.

PECS has obtained best results in patient-professional communication especially in the outpatient setting. This visual schedule system along with the weekly visits was successful in helping children complete more of steps of the appointment. The process also progressed at a quicker rate and the children showed much less amount of distress in their behaviour during the dental appointment in comparison to the traditional methods like tell-show-do ${ }^{[17]}$.

\section{Anaesthesia techniques}

\section{Sedation via submucosal route during dental treatment}

Sedation should be used as a last resort, when behavioural management techniques have been tried. Sedation is performed through different routes such as inhalational, intravenous, intramuscular ${ }^{[18]}$. Submucosal route of drug administration is considered very quick and produces adequate sedation when administered in maxillary buccal submucosa. Hence this can be used as an alternative to general anaesthesia but so far only a few studies have compared its usage with other routes of drug administration $[19,20]$.

A case report from Yonsei University was published describing the successful case of management of behaviour during dental procedures by administering $9 \mathrm{mgs}$ of midazolam via a submucosal route. The level of sedation acquired after 5 minutes of drug administration was conscious sedation where the airway is still under patient control and he/she can move his/her head and body, either of which didn't alter the treatment. Throughout the treatment $\mathrm{O}_{2}$ was continuously administered. After 30 minutes the patient recovered from the sedation which is very quick compared to general anaesthesia. However, there are some side effects of using sedation through submucosal route such as discomfort at the spot of injection, respiratory depression and vomiting reflex. The side effects vary for individual patients with autism, thus it is important to understand the clinical situation of individual patients in order to administer sedation via submucosal route ${ }^{[18]}$.

Summary of literature on current dental interventions in treating children with autism that emerged from the thematic analysis. 
Table 8: Summary of the results

\begin{tabular}{|c|c|c|c|c|c|c|}
\hline Authors & \begin{tabular}{c|} 
Study \\
design
\end{tabular} & $\begin{array}{c}\text { Population group and } \\
\text { clinical diagnosis }\end{array}$ & $\begin{array}{c}\text { Study } \\
\text { instrument }\end{array}$ & age & intervention & Outcome \\
\hline $\begin{array}{c}\text { Marion et al. } \\
\text { 2016. }\end{array}$ & \begin{tabular}{|c|} 
Quasi \\
experimental \\
design
\end{tabular} & $\begin{array}{c}\text { children who have } \\
\text { Autism and their Care } \\
\text { givers }\end{array}$ & Surveys & $1-18$ years & $\begin{array}{l}\text { Desensitization like } \\
\text { Video-Dental stories }\end{array}$ & $\begin{array}{l}\text { It was found that use of preparatory aids } \\
\text { like video dental stories was very useful in } \\
\text { preparing the child for dental treatment }\end{array}$ \\
\hline $\begin{array}{l}\text { Murshid, } \\
\text { E.Z., } 2017 \\
{[11]}\end{array}$ & $\begin{array}{l}\text { Cross } \\
\text { sectional } \\
\text { study }\end{array}$ & Children with autism & Questionnaire & 6 years & $\begin{array}{l}\text { Desensitization like } \\
\text { dental stories }\end{array}$ & $\begin{array}{l}\text { Results showed half of the parents felt that } \\
\text { preparatory aids were useful in preparing } \\
\text { children for dental treatment and follow } \\
\text { up survey revealed the increase in parent's } \\
\text { knowledge. }\end{array}$ \\
\hline $\begin{array}{l}\text { Anders on } e t \\
\text { al. } 2017[13]\end{array}$ & $\begin{array}{l}\text { Qualitative } \\
\text { study }\end{array}$ & $\begin{array}{c}\text { Dental and } \\
\text { communication } \\
\text { sciences and disorders } \\
\text { students }\end{array}$ & $\begin{array}{l}\text { Semi- } \\
\text { structured } \\
\text { interviews }\end{array}$ & NA & $\begin{array}{l}\text { Inter-professional } \\
\text { education } \\
\text { collaborative (IPEC) }\end{array}$ & $\begin{array}{l}\text { Results showed the in-depth } \\
\text { understanding of nature of autism by the } \\
\text { dental students and lead to development of } \\
\text { successful visual strategies for children } \\
\text { with autism on dental chair. }\end{array}$ \\
\hline $\begin{array}{l}\text { Fakhruddin } \\
\text { and Batawi } \\
2017^{[16]}\end{array}$ & $\begin{array}{l}\text { Clinical } \\
\text { study }\end{array}$ & Children with autism & Questionnaire & (6 to 9 years) & $\begin{array}{l}\text { Audio-visual } \\
\text { distraction like } \\
\text { Video googles }\end{array}$ & $\begin{array}{l}\text { Effective in enhancing the quality of } \\
\text { edental assessment and increased the } \\
\text { anxiety as well as uncooperative } \\
\text { behaviours. }\end{array}$ \\
\hline $\begin{array}{l}\text { Isong et al. } \\
2014^{[12]}\end{array}$ & $\begin{array}{c}\text { Randomised } \\
\text { controlled } \\
\text { trial }\end{array}$ & Children with autism & $\begin{array}{c}\text { Venham } \\
\text { anxiety score } \\
\text { and behaviour } \\
\text { scores were } \\
\text { analysed } \\
\end{array}$ & $\begin{array}{l}\text { ( } 7 \text { to } 17 \\
\text { years) }\end{array}$ & \begin{tabular}{|lr} 
Video & peer \\
modelling & Video \\
goggles/D VD &
\end{tabular} & $\begin{array}{l}\text { After calculating the mean anxiety score } \\
\text { ond behaviour scores it is found that the } \\
\text { patient turned more cooperative and } \\
\text { understanding than the control group. }\end{array}$ \\
\hline Jo et al. 2017 & $\begin{array}{l}\text { Clinical } \\
\text { study }\end{array}$ & Child with autism & $\begin{array}{l}\text { Follow up } \\
\text { results }\end{array}$ & 19 years & $\begin{array}{l}\text { Submucosal route of } \\
\text { drug administration }\end{array}$ & $\begin{array}{l}\text { Study showed that submucosal route of } \\
\text { drug administration is better than other } \\
\text { types as it is effective in managing the } \\
\text { behaviour. }\end{array}$ \\
\hline $\begin{array}{l}\text { Mah and } \\
\text { Tsang, 2016 } \\
{[21]}\end{array}$ & $\begin{array}{c}\text { Randomised } \\
\text { control trial }\end{array}$ & Children with autism & & (3-8 years) & schedule & $\begin{array}{l}\text { Results showed that patients that were } \\
\text { given visual schedule along with the tell- } \\
\text { show-do technique have performed the } \\
\text { tasks more faster with less dental fear. }\end{array}$ \\
\hline $\begin{array}{l}\text { Nelson } \text { et al. } \\
2015^{[14]}\end{array}$ & $\begin{array}{l}\text { Systematic } \\
\text { review }\end{array}$ & Children with autism & NA & NA & $\begin{array}{l}\text { Educational } \\
\text { therapeutic } \\
\text { behavioural } \\
\text { approaches }\end{array}$ & $\begin{array}{l}\text { By taking time to understand each child } \\
\text { and their development it is easy to treat } \\
\text { them along with including the educational } \\
\text { strategies that are normally used to treat } \\
\text { them in medical settings }\end{array}$ \\
\hline $\begin{array}{l}\text { Zink et al. } \\
2016^{[17]}\end{array}$ & $\begin{array}{c}\text { Longitudinal } \\
\text { study }\end{array}$ & Children with autism & $\begin{array}{c}\text { Statistical } \\
\text { analysis, Kiviat } \\
\text { chart }\end{array}$ & $(5-19$ years $)$ & $\begin{array}{l}\text { Picture exchange } \\
\text { Communication } \\
\text { system }\end{array}$ & $\begin{array}{l}\text { Improvement in the patient-professional } \\
\text { communication is seen during the } \\
\text { treatment. }\end{array}$ \\
\hline $\begin{array}{l}\text { Elmore } \text { et al. } \\
2016^{[22]}\end{array}$ & $\begin{array}{l}\text { Literature } \\
\text { review }\end{array}$ & Children with autism & Themes & NA & $\begin{array}{l}\text { Picture Cards } \text { Video } \\
\text { technology r and } \\
\text { mobile applications. }\end{array}$ & $\begin{array}{l}\text { Use of technology such as videos and } \\
\mathrm{d} \text { applications can help in reducing the } \\
\text { anxiety related to the dental treatment and } \\
\text { also increases the social awareness. }\end{array}$ \\
\hline
\end{tabular}

\section{Discussion}

Dental treatment for children with autism can be quite challenging, these challenges may arise as a result of communication difficulties, attention deficits, uncooperative behaviours, anxiety, impaired executive function, sensory deficits and dietary factors ${ }^{[3]}$. A variety of strategies can be adopted by dentists to enhance the treatment outcome. This review provides an overview of a range of current strategies found to be effective. These strategies are discussed below. As education is foundation for anything importance of introducing a subject called inter-professional collaboration and their increased knowledge in creating visual strategies was clearly explained by Anderson and his colleagues by conducting semi-structured interviews in his qualitative study. However due to the smaller number of patients $(n=4)$ allocated to the groups of students containing dental professionals and communication sciences, many diversified risk factors could not be experienced, and this research motivates other researchers to conduct more studies on interprofessional collaboration to measure the relevance of it in this field ${ }^{[13]}$.

Treatment protocol used for the typically developing children varies a lot because of having good understanding capacity and less anxiety ${ }^{[11]}$ but while treating children with autism a perfect protocol needs to be followed not only in the dental chair but also before entering the dental clinic to increase the knowledge about dental treatment and daily oral activities like brushing in the form of dental stories [10]. All the studies emphasised on the importance of the introduction of new dental strategies in children with autism but only 3 studies explained the importance of having a proper customised treatment strategy. The studies which emphasised on use of dental stories as a means of desensitization has a lot of positive feedback from the caregivers, also these studies recommended the importance and requirement of creating personalised dental stories according to the preferences of a child by dental professionals.

Fakhruddin and Batawi in their clinical study conducted to evaluate the effectiveness of the audio-visual distraction has clearly articulated the appointment schedules rather than directly experimenting audio-visual distraction strategy, he scheduled desensitization appointment initially where child's sensitivities were assessed and caregiver's interview is taken, after assessment and interview, a list is prepared in which all the stimuli that upsets the child are noted. Later it is observed if the dentist could provide any accommodation to comfort 
and get rid of unwanted stimuli. Then, introduction of tooth models, showing how the suction, air- water syringe cavity drilling instruments feels, and works was clearly explained in a very friendly manner to desensitize the auditory, visual and tactile sensations of the children and to build future communication with the dentist and the dental environment, later he used audio visual distraction through the eyewear displaying a cartoon movie ${ }^{[16]}$. Audio-visual distraction found to be very effective as $75 \%$ of children who were randomised to video goggles and peer video modelling in a study of Isong et al. were calm on the dental chair during the treatment. Video peer modelling is a very effective means of verbal and non-verbal communication before and during the dental visit for instance, a child can imitate sitting in a dental chair, leaning back by watching the video ${ }^{[12]}$.

In comparison with the tell-show-do technique picture exchange communication system found to be more useful in simplifying the environment of work along with creating opportunity for patient- professional communication however the children who had past experiences with the dentists in the longitudinal study conducted by Zink took a lot of attempts in completing the tasks than children who didn't had previous dental experience ${ }^{[17]}$.

Not all the children with autism need the treatment under general anaesthetics procedures, putting this technique as last call for any dentist and Jo et al. in their study explained the effectiveness of using submucosal route of sedation when all the behavioural approaches fail, and even intra-muscular or intra-venous routes of sedation fail due to the obstruction of physical restraints like Pedi wraps ${ }^{[18]}$.

\section{Limitations}

- Consideration of only academic journals is a main drawback of this study as there is a lot of grey's literature in the government sites and issue papers on this study

- There is a lot of literature in some of the journals like paediatrics dentistry which was not accessible.

- Though there are really reliable works have got published in other languages like French and Spanish only English literature is considered.

\section{Conclusion and future recommendations}

There are a lot of current strategies in this review for a dental professional to treat the children with autism.

Some of the future recommendations in addition to the current existing strategies include the need of comparative studies for the use of submucosal route of anaesthesia administration. Though submucosal route of local anaesthesia is more effective than the other routes because of its fast action as it is not affected by the first pass metabolism in the liver but there are limited comparative studies to explain the profound use of submucosal route of drug administration ${ }^{[18]}$. World Health Organisation has linked inter professional collaboration with good outcomes with family health, infectious diseases and non-communicable diseases but not yet in the field of dentistry and special needs due to the lack of evidence ${ }^{[23]}$. Hence there is a desperate need in the high quality evidence in the emerging field like inter-professional collaboration (collaboration of speech pathologists, occupational therapists, communication sciences and diseases with the dentists) as collaboration increase the opportunity to learn and think beyond the traditional way, access to professionals we would rarely reach to serve a large number of people, more importantly it increases the knowledge and insight into both the fields and pools knowledge and create space of innovative ideas beneficial for their future practice. The high-speed internet and extreme use of mobile devices for almost all the purposes has increased the downloadable applications in them, as this device are very portable it allows a person to have access to it almost everywhere and every time ${ }^{[22]}$. This can be valuable in educating the children with autism who can be beneficial from repetition of the content while learning the social skills and new procedures like brushing, dental visit.

This review explored to find the current dental strategies for children with autism has shown an enormous potential to help children cope with dental treatments and extending the knowledge of dental practitioners. It explained how lack of social skills can make the treatment difficult by providing the evidence of increased knowledge of care givers and children after using dental stories as desensitizing strategy. Early familiarization with the dental clinic would not make the child over-whelmed during the treatment. The review provided the details about importance of some of the new strategies like introducing inter-professional collaboration as a part of university dental education, visual strategy like use of electronic media on the dental chair in the form of video goggles which can serve as the best audio-visual strategy and very conservative anaesthesia techniques like submucosal route of drug administration. However, due to the heterogeneous nature of the children with autism it was very difficult to find one such extraordinary strategy that fits all.

\section{References}

1. Gandhi RP, Klein U. Autism spectrum disorders: an update on oral health management. Journal of Evidence Based Dental Practice 2014;14:115-126.

2. World Health Organization. Autism spectrum disorders 2017.

3. Cruz VSA, Cruz TAAA, Flag MAS, Gomes DDR, De Carvalho Silva LT, Dos Santos VDCB. Conditioning strategies in the dental care of patients with autism spectrum disorders. Revistas 2017;74(4):294.

4. Bartolomé-Villar B, Mourelle-Martínez MR, DiéguezPérez M, De Nova-García MJ. Incidence of oral health in paediatrics patients with disabilities: Sensory disorders and autism spectrum disorder: Systematic review II. Journal of clinical and experimental dentistry 2016;8(3):e344.

5. Delli K, Reichart PA, Bornstein MM, Livas C. Management of children with autism spectrum disorder in the dental setting: concerns, behavioural approaches and recommendations. Medicina oral, patologia oral y cirugia bucal 2013;18(6):e8-62.

6. Shattuck PT, Roux AM, Hudson LE, Taylor JL, Maenner MJ, Trani JF. Services for adults with an autism spectrum disorder, The Canadian Journal of Psychiatry 2012;57(5):284-91.

7. Munn Z, Moola S, Riitano D, Lisy K. The development of a critical appraisal tool for use in systematic reviews addressing questions of prevalence, International journal of health policy and management 2014;3(3):123.

8. Hannes K, Lockwood C, Pearson A. A comparative analysis of three online appraisal instruments' ability to assess validity in qualitative research, Qualitative health research 2010;20(12):1736-43.

9. Critical Appraisal Skills Programme. CASP 2019.

10. Marion IW, Nelson TM, Sheller B, McKinney CM, Scott JM. Dental stories for children with autism. Special Care in Dentistry 2016;36(4):181-186.

11. Murshid EZ. Effectiveness of a preparatory aid in 
facilitating oral assessment in a group of Saudi children with autism spectrum disorders in Central Saudi Arabia. Saudi Medical Journal 2017;38(5):533.

12.Isong IA, Rao SR, Holifield C, Iannuzzi D, Hanson E, Ware $\mathrm{J}$ et al. Addressing dental fear in children with autism spectrum disorders: a randomized controlled pilot study using electronic screen media. Clinical pediatrics 2014;53(3):230-237.

13. Anderson KL, Self TL, Carlson BN. Inter professional Collaboration of Dental Hygiene and Communication Sciences \& Disorders Students to Meet Oral Health Needs of Children with Autism. Journal of allied health 2017;46(4):97E-101E.

14. Nelson TM, Sheller B, Friedman CS, Bernier R. Educational and therapeutic behavioral approaches to providing dental care for patients with Autism Spectrum Disorder. Special Care in Dentistry 2015;35(3):105-113.

15. Bodison SC, Parham LD. Specific sensory techniques and sensory environmental modifications for children and youth with sensory integration difficulties: A systematic review. American Journal of Occupational Therapy 2018;72(1):72011900401-720119004011.

16. Fakhruddin KS, El Batawi HY. Effectiveness of audiovisual distraction in behavior modification during dental caries assessment and sealant placement in children with autism spectrum disorder. Dental Research Journal 2017;14(3):177.

17.Zink A, Diniz M, Rodrigues Dos Santos M, Guaré R. Use of a Picture Exchange Communication System for preventive procedures in individuals with autism spectrum disorder: pilot study. Spec Care Dentist 2016;36(5):254-9.

18. Jo CW, Park CH, Lee JH, Kim JH. Managing the behavior of a patient with autism by sedation via submucosal route during dental treatment. Journal of dental anesthesia and pain medicine 2017;17(2):157-161.

19. Baek K. Considerations for submucosal midazolam administration in combination with oral and inhaled medications for sedation of pediatric dental patients. J Dent Anesth Pain Med 2015;15:47-52.

20. Song YU, Webb MD. Comparison of the effect of orally versus submucosally administered meperidine on the behavior of pediatric dental patients: a retrospective study. Anesth Prog 2003;50:129-133.

21. Mah JW, Tsang P. Visual schedule system in dental care for patients with autism: A pilot study. Journal of Clinical Pediatric Dentistry 2016;40(5):393-399.

22. Elmore JL, Bruhn AM, Bobzien JL. Interventions for the Reduction of Dental Anxiety and Corresponding Behavioral Deficits in Children with Autism Spectrum Disorder. Journal of Dental Hygiene 2016;90(2):111-20.

23. World Health Organization. Framework for Action on Inter professional Education and Collaborative Practice. Geneva: World Health Organization 2010.

24. Mathu-Muju KR, Hsin-Fang L, Nam LH, Bush HM, Li. Visualizing the Comorbidity Burden in Children with Autism Spectrum Disorder Receiving Dental Treatment Under General Anesthesia, Pediatric Dentistry. 2016; 38(2):134-9.

25. Shree PC, Rakshagan V, Dhanraj S, Jain AR. Knowledge, attitude, and practice on oral hygiene status in autistic children, Drug Invention Today 2018;10:2115-9.

26.Zafar S, Boyd D, Siddiqi A. Dental Management of a Child with Autism Spectrum Disorder and AttentionDeficit Hyperactivity Disorder. 